\title{
PENGARUH SEDUH COKLAT DAN PIJAT COUNTEPRESSURE TERHADAP PENURUNAN NYERI PERSALINAN DAN KEMAJUAN DILATASI SERVIKS
}

\author{
Sendy Firza Novilia $\mathbf{T}^{*}$ \\ STIKES William Booth Surabaya, Jln. Cimanuk No. 20, Telp. (031) 5633365 \\ sendyfirza@gmail.com
}

\begin{abstract}
Abstrak
Nyeri persalinan merupakan keadaan fisologis yang dialami ibu selama proses persalinan. Dampak nyeri persalinan adalah terjadinya pembengkakan serviks dan vagina yang membahayakan kondisi ibu dan janin. Seduh coklat dan pemberian pijatan Counterpressure merupakan tindakan komplementer untuk menciptakan kenyamanan.Tujuanmini riset iniuntukmengetahuiadakah pengaruh dari seduh coklat dan pemberian pijatan counterpressureterhadap penurunan nyeri persalinan dan kemajuan dilatasi serviks.Penelitian ini merupakan mini riset dengan desain penelitian studi kasus bentuk tunggal (One Shot Case Study) dengan jumlah sampel penelitian 6 orang bedasarkan kriteria yaitu primigravida inpartu kala 1 fase aktif yang dibagi menjadi dua kelompok yaitu kelompok perlakuan dan kelompok kontrol dan kedua kelompok dinilai menggunakan Numerik Ratting Scale (NRS) untuk menilai perubahan nyeri persalinan dan melakukan pemerikasaan dalam untuk mengetahui ada atau tidaknya kemajuan persalinan.Hasil dari mini riset pada kelompok perlakuan mengalami kemajuan persalinan dengan durasi 3-5 jam pada kala 1 fase aktif dengan skala nyeri ringan dibandingkan kelompok kontrol dengan durasi pembukaan serviks lebih panjang 6-8 jam pada kala 1 fase aktif dengan nyeri sedang hingga berat sehingga dapat disimpulkan bahwa ada pengaruhpemberian seduh coklat dengan pijat counterpressur terhadap penurunan nyeri persalinan dan kemajuan dilatasi serviks pada kala 1 fase aktif.
\end{abstract}

Kata kunci :Nyeri persalinan, dilatasi serviks, seduh coklat dan pijat counterpressure 


\section{PENDAHULUAN}

Angka KematianIbu (AKI) merupakan salah satu indicator dari status kesehatan masyarakat. Angka kematian ini di Indonesia masih tinggi bila dibandingkan dengan negara lain. Menurut World Health Organization (WHO) diperkirakan setiap tahunnya terjadi 210 juta kehamilan di seluruh dunia, dari jumlah itu terdapat 20 juta perempuan yang mengalami kesakitan akibat kehamilan (Prawirohardjo, 2008). Berdasarkan hasil Survey Demografi Kesehatan Indonesia SDKI tahun 2012 yang menunjukkan AKI di Indonesia masih tinggi yaitu 359 per 100.000 kelahiran hidup jika terhitung dalam jiwa maka hal tersebut terhitung sekitar 16.155 jiwa ibu yang meninggal akibat kehamilan dan persalinan.

Upaya menurunkan angka kejadian tersebut adalah dengan adanya penyediaan pelayanan kesehatan maternal dan neonatal yang berkualitas dan memadai bagi masyarakat.

Persalinan adalah proses dimana bayi, plasenta dan selaput ketuban keluar dari uterus ibu. Seorang ibu dalam menghadapi proses persalinan seringkali merasakan nyeri, cemas dan ketakutan. Kecemasan dan ketakutan ini sangat mempengaruhi system kerja otak dalam mempersepsikan rasa nyeri yang dirasakan oleh tubuh ibu. Rasa nyeri ini muncul sekitar 12-14 jam, Wall dan Melzack tahun 1994 dalam Danuatmaja (2008) menyatakan bahwa rasa nyeri harus dikurangi atau diturunkan dengan cara efektif, sebab bila terjadi rasa nyeri yang disertai kecemasan akan memiliki efek yang berbahaya terhadap ibu dan janin.

Nyeri persalinan merupakan perasaan keadaan yang fisiologis atau perasaan yang tidak nyaman yang dialami selama proses persalinan
(Klossner, 2006). Keadaan ini mulai timbul pada kala 1 yaitu di fase laten dan fase aktif. Nyeri persalinan ini dapat disebabkan dengan adanya kontraksi uterus, dilatasi serviks dan adanya penipisan serviks. Pada fase aktif terjadinya dilatasi serviks berlangsung selama 6 jam, yang dimulai dari pembukaan 4 hingga 7 . Primigravida pada kala 1 persalinan bias terjadi lebih dari 20 jam, sedangkan pada ibu multigravida dapat berlangsung lebih cepat yaitu 14 jam. Pada ibu hamil informasi dan pengalaman yang kurang dalam menghadapi nyeri persalinan masih cukup tinggi sehingga dapat menimbulkan rasa cemas dan ketakutan dalam menghadapi persalinan (Doriana, et al., 2010). Intensitas nyeri yang dirasakan selama persalinan akan mempengaruhi kondisi psikologis ibu, proses persalinan dan kesejahteraan janin (Potter \& Perry, 2010).

Nyeri persalinan dapat memberikan komplikasi pada ibu dan bayi seperti terjadinya perdarahan, gangguan pada system perkemihan, penglihatan kabur dan bayi lahir dengan prematur. Rasa nyeri, tegang dan rasa takut ini dapat menghasilkan sejumlah katekolamin atau hormon stress yang berlebihan. Peningkatan katekolamin dapat memperpanjang proses persalinan dan mengurangi efisiensi kontraksi uterus sehingga merugikan janin yang dapat menyebabkan trauma pada bayi dan meningkatkan pola jantung pada janin (Bonica JJ, 1995). Selain itu, menurut Hamilton (2005) menyatakan nyeri yang berlebihan pada ibu bersalin dapat menyebabkan keinginan untuk segera mengakhiri masa persalinan dan dapat menyebabkan pembengkakan pada rahim dan tidak adanya kemajuan 
dilatasi serviks sehingga terjadi distosia persalinan.

Tindakan pijat dan pemberian terapi sedu coklat merupakan tindakan komplementer untuk menciptakan kenyamanan, sesuai dengan teori Comfort dari Kolcaba (2014) yang mendefinisikan comfort adalah suatu keadaan yang dialami seseorang yang dapat diartikan sebagai suatu pengalaman immediate yang dijadikan sebagai kekuatan melalui kebutuhan terhadap keringanan (relief), ketenangan (ease), dan transcendence yang dapat terpenuhi dalam keempat konteks pengalaman tersebut, yaitu meliputi aspek fisik, psikospiritual, sosial dan lingkungan (Kolcaba, 2014).

Penatalaksanaan yang dapat dilakukan untuk mengurangi nyeri persalinan diantaranya dengan cara, tindakan farmakologi dan non farmakologi. Pada tindakan farmakologi yang kita ketahui yaitu dengan pemberian obat analgesik, suntikan epidural dan lain-lain. Tindakan farmakologi mempunyai efek samping, dimana obat dapat menembus plasenta sehingga mempengaruhi perkembangan dan pertumbuhan dari janin (Wong, 2008). Tindakan nonfarmakologi diantaranya relaksasi, pijat, counter pressure, akupuntur, akupresur, teknik nafas dalam, perubahan posisi dan terapi panas/ dingin serta pemberian terapi coklat. Chocolate merupakan Makanan yang digemari oleh sebagian besar penduduk dunia dan sudah dikenal sejak dahulu kala ini memiliki berbagai efek seperti meningkatkan kewaspadaan, bekerja sebagai pijat alami sehingga bias mengurangi rasa sakit, peredabatuk, dan menimbulkan rasa senang sehinngga kecemasan menurun. Selain itu konsumsi coklat dapat menurunkan stres pada orang yang sehat. Produk coklat dibagi menjadi coklat hitam (dark chocolate), coklat susu(milk chocolate), dan coklat putih (whitechocolate). Beberapa kandungan dalam coklat seperti kafein, teobromin, tiramin \& teobro- $\min$ menstimulasi otak dengan menghambat penyerapan adenosin, sedangkan PEA dan flavanol meningkatkan aliran darah ke otak menyebabkan lebih banyak oksigen yang masuk ke dalam otak, sehingga dapat meningkatkan kewaspadaan serta omega 3 yang mengandung senyawa kimia anti nyeri. Jenis coklat yang memiliki kandungan kimia tersebut paling tinggi adalah coklat hitam. Menurut penelitian terdahulu, mengkonsumsi produk coklat dapat mengurangi rasa nyeri kognitif selama12 jam. Tindakan non-farmakologi lebih digunakan, sebab lebih efektif, murah dan tidak memberikanefek yang merugikan pada janin (Astuti, 2009).

Nyeri persalinan pada kala I ditransmisikan dari serat eferen melalui pleksushipogastrik superior, inferior dan tengah, rantai simpatiktorakal bawah, dan lumbal ganglia akarsaraf posterior pada T10 sampai L1. Upaya yang dapat dilakukan untuk mengatasi nyeri tersebut adalah dengan pijat. Counter pressure adalah pijatan menggunakan tekanan kuat dengan cara meletakkan tumit tangan atau bagian datar dari tangan dan atau menggunakan bola tenis pada daerah lumbal dimana saraf sensorik rahim dan mulut rahim berjalan bersama dengan saraf simpatis rahim memasuki sumsum tulang belakang melalui saraf torakal 10-11-12 hingga sampai pada daerah lumbal (Ward and Shelton, 2009). Penelitian yang dilakukan oleh Hastamidkk., (2011), menunjukkan hasil bahwa teknik counter pressure dapat 
mengurangi rasa nyeri persalinan dibandingkan dengan tindakan meremas atau kneading. Teknik counter pressure dilakukan dengan posisi duduk atau berdiri membungkuk, dan dapat mempengaruhi pelepasan kadar endorphin secara efektif sehingga dapat menurunkan rasa nyeri persalinan.

Menurut Janssen, et al.,(2012) menyatakan bahwa nyeri persalinan dapat berkurang dengan tindakan pijat hal tersebut juga dapat dilihat dengan adanya proses kemajuan pada dilatasi serviks.

Sampai saat ini, efektivitas dari intervensi pijat counter pressure dan

\section{METODE PENELITIAN}

Penelitian ini merupakan mini riset dengan desain penelitian studi kasus bentuk tunggal (One Shot Case Study) dengan jumlah sampel penelitian 6 orang yang dibagi menjadi dua kelompok yaitu 3 ibu inpartu kala 1 fase aktif diberikan pijat counterpressure dan coklat dan 3 ibu inpartu kala 1 fase aktif tidak diberikan pijat counterpressure dan tidak diberikan coklat namun sebelumnya kedua kelompok dilakukan pemeriksaan dalam dan pengukuran skala nyeri terlebih dahulu menggunakan Numerik Ratting Scale (NRS) setelah diberikan perlakuan 4 jam kemudian akan dilakukan evaluasi ada atau tidaknya perubahan nyeri persalinan dan melakukan pemerikasaan dalam untuk mengetahui ada atau tidaknya kemajuan persalinan (pembukaan dilatasi serviks).Penelitiandilakukan di Puskesmas Batur 1 Kabupaten Banjarnegara pada Bulan JuliTahun konsumsi coklat terhadap perubahan nyeri persalinan dan kemajuan dilatasi serviks pada kala I fase aktif masih perlu dibuktikan. Penelitian yang terkait dengan pijat counter pressureterhadapperubahannyeripersali nanmasihterbatas. Berdasarkan uraian diatas maka peneliti tertarik untuk melakukan mini riset tentang "Pengaruh Seduh Coklat dan Pijat Counter Pressure TerhadapPerubahan Nyeri Persalinan dan Kemajuan Dilatasi Serviks pada Kala I FaseAktif di Puskesmas Batur 1 Kabupaten Banjarnegara

2018. Variabel independen yaitu pijat counterpressure dan coklat, variabel dependen terdiri dari penurunan nyeri persalinanan dan kemajuan dilatasi serviks.

HASIL DAN PEMBAHASAN

Hasil

Tabel 1 Hasil Analisa Data Uji Normalitas Data kontrol dan perlakuan

\begin{tabular}{lllll}
\hline No. & Hasil & Sig & df & $\begin{array}{l}\text { P } \\
\text { value }\end{array}$ \\
1. & Perlakuan & .750 & 3 & .000 \\
2. & Kontrol & 1.000 & 3 & 1.000 \\
\hline \multicolumn{4}{l}{ SumberData : Data Primer Juli 2018}
\end{tabular}

Berdasarkantabel 1. diperolehhasil uji normalitas data kelompok kontrol dan kelompok perlakuan menggunakan uji Shapiro wilkdiperolehnilai $\mathrm{p}$ value pada kelompok perlakuan nilai $\mathrm{p}$ value 0.000 dimananilai $\mathrm{p}$ value <nilai $\alpha(0.05)$ berartibahwa data pada kelompok perlakuanberdistribusi tidak normal, sedangkanhasilnilai $\mathrm{p}$ value pada 
kelompok kontroladalah1.000

dimananilai $\mathrm{p}$ value >nilai $\alpha(0.05)$ berartibahwa data pada kelompok kontrol berdistribusitidak normal, sehinggahasil uji statistic dilanjutkanmenggunakan uji Non Parametrikyaitumenggunakan uji Mann Whitneykarena data berdistribusitidak normal pada data kelompok kontrol dan dengan sampel yang tidak berpasangan.

Tabel 2 Hasil Analisa Data Penurunan Nyeri dan Kemajuan Dilatasi Serviks Kelompok Perlakuan dan Kelompok Kontrol

No. Hasil Mean SD

\section{Perlakuan 2,33}

2. Kontrol 4,67

SumberData : Data Primer Juli 2018

Berdasarkantabel

2.

Diperolehnilai mean pada kelompok kontrol nilai mean 4,67 pada kelompok perlakuan pijat counterpressuredan coklat nilai mean yaitu2,33artinyabahwaterjadipenurunan nyeri persalinan dan kemajuan dilatasi serviks sebesar $10 \%$ dari kelompok kontrol dimanapijat couterpressur dan konsumsi coklat pada kelompok perlakuan mengalami kemajuan dilatasi serviks pada fase aktif terhitung dari pembukaan 4 hingga 10 dengan durasi waktu 4-6 jam dan skala nyeri kategori nyeri sedang (4-6).

$\begin{array}{lrr}\text { Berdasarkan uji } & \text { statistic } \\ \text { menggunakan uji } & \text { Mann } \\ \text { Whitneydiperolehnilai } \quad \text { p } & \text { value } \\ 0,105 \text { dimananilai p value }>\text { nilai } \alpha & (0.05) \\ \text { yang berartibahwatidakadapengaruh }\end{array}$

pijat counterpressure dan konsumsi coklat terhadap penurunan nyeri persalinan dan kemajuan dilatasi serviks pada kala 1 fase aktif di Puskesmas Batur 1 Kabupaten Banjarnegara.

\section{Pembahasan}

Berdasarkan uji statistikdiperolehtidakadapengaruhantar apemberianintervensipijatcouterpressure dan konsumsi coklatterhadap penurunan nyeri persalinan dan kelajuan dilatasi serviks kala 1 fase aktif walaupun mengalami kemajuan dan penurunan skla nyeri sebesar $10 \%$ namun kurang Psignifikan dikarenakandurasiwaktudan valyiemlah sampel yang sedikit.

3 0,10denurut Retty Nirmala dengan 3 penelitiannya "efektifitas pijat efflurage dengan couterpressur terhadap penurunan nyeri persalianan dan kemajuan dilatasi serviks didapatkan hasil rerata dilatasi serviks pada kelompok counterpressure sesudah diberikan intervensi sebesar 8,03 lebih besar dari kelompok effleurage dengan nilai rerata 7,47 dengan nilai $p 0,00$ $(p<0,05)$ yang mempunyai arti bahwa kedua kelompok tersebut terdapat perbedaan yang bermakna pada dilatasi serviks antara kelompok pijat effleurage dan kelompok counterpressure. Perbedaan rerata nyeri persalinan pada kedua kelompok sebesar 0,03. Secara klinis nilai perbedaan tersebut $<20 \%$ yang artinya bahwa tidak terdapat perbedaan yang bermakna secara klinis, sedangkan pada perbedaan rerata dilatasi serviks kedua kelompok sebesar 0,71 perbedaan tersebut secara klinis 
menunjukkan bahwa nilai >20\% yang artinya terdapat perbedaan secara klinis pada dilatasi serviks pada kedua kelompok tersebut (Sopiyudin, 2009). Hal ini hampir sependapat dengan hasil penelitian ini yakni pijat couterpressure dan konsumsi coklat tidak ada pengaruh dalam penurunan nyeri dan kemajuan dilatasi serviks walaupun secara klinis terdapat perubahan yang bermakna $10 \%$ namun belum signifikan hal ini dikarenakan waktu dan jumlah sampel yang terlalu sedikit.

\section{KESIMPULAN}

Berdasarkanhasilpembahasandiatas bahwa tidak ada pengaruhpijat counterpressur dan konsumsi coklat terhadap penurunan nyeri persalinan dan kemajuan dilatasi serviks pada kala 1 fase aktif dikarenakanketerbatasandurasiwaktupen elitiandan jumlah sampel yang sedikitsedangkan pada penelitian lain terdapat pengaruhkarenadurasiwaktudan jumlah sampel yang cukup.

\section{SARAN}

Saran yang dapat di berikanadalahtenagakesehatandapatmen ggunakanterapipijatcouterpressur dan konsumsi coklat untuk penurunan nyeri persalinan dan kemajuan dilatasi serviks pada kala 1 fase aktif durasiwaktusesuaisehingga mendapatkan hasil yang maksimal danmetodeini juga dapatditerapkan pada pelayanankebidananbagiibuhamil, bersalin dan nifassecaraumum.

\section{DAFTAR PUSTAKA}

Akbarzadeh M., Zahra, M., Mohammad, J. H., Maryam, K., dan Najaf, Z. (2014). Comparison of the Effects of Maternal Supportive Care and Acupressure (BL32 Acupoint) on Pregnant Women's Pain Intensity and Delivery Outcomes. Journal of Pregnancy.Diunduhtanggal 06 Juli 2018. Jam 20.45 WIB di http://

http://www.ncbi.nlm.nih.gov/pm c/articles/

Akbarzadeh M., Zahra, M., Najaf, Z., dan Farideh, V. (2015). Comparison of the Effects of Doula Supportive Care and Acupressure at the BL 32 Point on the Mother's Anxiety Level and Delivery Outcome. Iranian Journal of Nursing and Midwifery Research. Diunduhtanggal 06 Juli 2018. Jam $22.15 \quad$ WIBdi http://www.researchgate.net/pub lication

Arikunto,S.

ProsedurPenelitianSuatuPendek atanPraktik. Jakarta: RinekaCipta

Hapsari R., Anasari Tri. (2013). Efektifitas Teknik RelaksasiNafasDalam Dan MetodePemberianCoklatTerhada pPenurunanIntensitasDesminore Pada Remaja Putri di SMK 
Swagaya 2 Purwokerto. Journal

Of Midwifery Science.

DiunduhTanggal 7 juli 2018,

Jam 22.12 WIB di

http://ejournal.stikesmukla.ac.id/

index.php/involusi/article/view/3

$\underline{9}$

Nirmala S. (2017). EfektifitasPijat Effleurage dan Counterpressure TerhadapPenurunan Nyeri

Persalinan Dan

KemajuanDilatasiServiks Pada

Kala 1 FaseAktif di

BidanPraktikMandiri Surabaya.

Journal Electronik Theses

\&Disertations

(ETD).

DiunduhTanggal 5 Juli 2018,

Jam 21.27 WIB di

http://etd.repository.ugm.ac.id/

OktaviaLaily., Ulfa M. (2016).

PengaruhKonsumsiDark

ChocolateTerhadapKecemasan

Pada Ibu Post Sectio Caesarea.

Journal Ners dan Kebidanan.

Volume 3, No 2.

DiunduhTanggal 7 Juli 2018,

Jam 22.15 WIB di

https://www.e-

jurnal.com/2018/07/pengaruh-

$\underline{\text { konsumsi-dark-chocolate.html }}$

Pasongli S., Rantung M., Pesak E. (2014). Efektifitas

Counterpressure

TerhadapPenurunanIntensitas

Nyeri Kala I

FaseAktifPersalinan Normal di

RumahSakit Advent Manado.

Journal IlmiahBidan.

DiunduhTanggal 7 juli 2018,
Jam 21.23 WIB di https://www.neliti.com/id/public ations/ 